\title{
Seismic Performance of RC Moment Frame Structures Made with EAF Slag Aggregates
}

\author{
Flora Faleschini, Mariano A. Zanini and Klajdi Toska \\ Dept. of Civil, Environmental and Architectural Engineering, University of Padova, Via Marzolo 9 \\ 35131-Padova, Italy, flora.faleschini@dicea.unipd.it, marianoangelo.zanini@dicea.unipd.it, \\ klajdi.toska@dicea.unipd.it
}

\begin{abstract}
Sustainability in the construction industry is becoming everyday more a major issue in todays world. To accomplish sustainability goals, adopted also by the Agenda 2030 of the United Nations, wide research has been carried out in the past years. Among this, the use of recycled aggregates has been proven to be promising both in terms of sustainability and material properties. Electric Arc Furnace (EAF) concrete has demonstrated a significant increase in mechanical properties when compared to natural aggregates (NA) ones. However, the mechanical properties enhancement is accompanied by an increase of its specific weight and the overall effects of its use in RC structures subjected to dynamic loads, has not been investigated yet. The present study aims to investigate the seismic reliability of reinforced concrete frame buildings made with EAF in comparison to the same structural configurations made with NA concrete, considering three different configurations (3-, 6- and 9- story building type) designed considering ordinary concretes made with natural aggregates.
\end{abstract}

Keywords: EAF Slag, Reinforced Concrete, Seismic Fragility, Seismic Reliability.

\section{Introduction}

Sustainability is one of the global challenges that the construction industry must face in the near future. The 2030 Agenda of the United Nations sets as one of its main goals waste generation reduction and promotes policies of prevention, reduction, reuse, and recycling. Lately great effort has been made by the research community on the promotion of recycling and reuse opportunities of waste materials in the construction industry. One of the most remarkable cases of recycling is the Recycled Aggregates (RAs) production by Construction and Demolition Waste (C\&DW) and their use is now regulated in most countries around the world (FHWA, 1997; EN 12620:2008; NTC, 2018). More recently, waste originating from industrial processes, have been object of research to evaluate their possible use to produce RAs or socalled industrial aggregates. Among other industrial waste or by-products, those coming from steelmaking industry, particularly electric arc furnace (EAF) slag, offer great performance when used in structural concrete. In previous research has been observed that EAF slag use in concrete mixtures improves both mechanical strength (Pellegrino et al., 2009; Arribas et al., 2015; Rondi et al., 2016; Liapis et al., 2018; Qasrawi, 2014) (i.e compressive strength, tensile strength and elastic properties) and durability (Faleschini et al., 2015; Pellegrino et al., 2012; Ortega-López et al., 2018) when compared to concrete mixtures with ordinary ones. In addition, heavy-weight metals present in the EAF slag composition give to EAF concrete mixtures a higher specific weight with respect to NA mixtures.

Experimental work on the behavior of EAF concrete has been carried out also at the element scale. They have shown that reinforced concrete (RC) elements with EAF slag aggregates manifest better flexural and shear capacity with respect to ordinary $\mathrm{RC}$ when tested to 
monotonic loading under four-point bending (Pellegrino et al., 2013; De Domenico et al., 2018). Axially loaded columns have shown a similar ductility to that of NA mixtures (Lee et al., 2018) while a higher shear capacity of exterior beam-column joint is observed (Faleschini et al., 2017). Laboratory tests on real scale EAF concrete joints under cyclic loading have shown gain with respect to NA ones in terms of ductility, dissipated energy and reduced cracking patter. Similar results were observed also for joints with lower cement content (Faleschini et al., 2017). The use of EAF slag has shown enhanced ultimate and frictional bond strength with respect to conventional concrete (Faleschini et al., 2017). Other beam-column joint conditions (i.e., strong beam - weak column and strong column - weak beam situations) have been numerically investigated (Faleschini et al., 2017).

The results of the research work reported above have shown that EAF concrete can be suitably applied in gravity structures and in special facilities that require shielding from radiations where its high specific weight and high strength can be better exploited (Pomaro et al., 2019). However, its efficiency is not so obvious when applied in elevation RC structures that are located in seismic regions where an important change of the building mass and stiffness can lead to a significant increase of the seismic loads in the structure. The present paper aims to study this topic, analyzing the seismic behavior of code conforming RC frame buildings built with ordinary concrete then replaced with three different classes of EAF concrete characterized by increasing aggregates replacement ratio. A dataset of experimental tests based on two previous research works of the same authors is used to define the mechanical properties of EAF concrete mixtures (Pellegrino et al.,2016; Zanini, 2019). Via statistical analysis, ratios of
variation of the main mechanical properties (i.e. compressive and tensile strength, and elastic
moduli) and of the specific weight were defined for three EAF concrete classes (C1, C2, A)
with respect to a benchmark mixture made with NAs. Three different geometrical
configurations of regular RC frame structures with three, six and nine stories were designed
according to the current Italian code for Constructions for a medium-to-high seismic hatard site. Fragility functions were then computed from the seismic responses of the analyzed

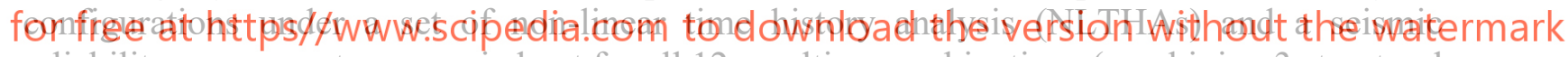
reliability assessment was carried out for all 12 resulting combinations (combining 3 structural configurations and 4 concrete mixes), investigating the variation of structural safety margins related to the use EAF concrete mixtures in replacement to a conventional NA concrete.

\section{EAF Slag Concrete and RC Frame Case Studies}

EAF slag is a by-product of the steelmaking industry which, after cooling from temperatures up to $1300{ }^{\circ} \mathrm{C}$ to ambient conditions, becomes a dark-grey stony material. EAF slag properties depend on the type of steel to be produced, scrap composition, slag cooling method and speed, and further weathering process. EAF aggregates present a rough texture and angular shape which influences bond development in the cement matrix since crushed stones present higher surface-to-volume ratio and require more cement paste to obtain a workable mixture in respect to NAs. The main physical properties of the slag for two size fractions, compared to a dolomitic aggregate, are reported in Table 1.

Generally, when used to replace NAs, EAF slag has a positive effect on the mechanical properties. However, the properties of the mixture strongly depend on type and amount of substitution. It has been experimentally proven that coarse aggregates have a beneficial effect, 
while when fine fraction is used the beneficial effect is more limited(Pellegrino et al., 2012). Compared to standard NA concrete, the EAF mixtures have higher specific weight about 3.3 $4.0 \mathrm{t} / \mathrm{m} 3$ against $2.7 \mathrm{t} / \mathrm{m} 3$ of normal ones. Particular attention must be paid to the segregation phenomena. High specific weight can result in insufficient viscosity of the cement paste causing the migration of the two phases. Elastic modulus is also enhanced when using EAF slag. This is mainly because concrete elastic modulus depends mainly on the aggregates elastic modulus. The overall property improvements are also due to the interfacial transition zone (ITZ) between EAF aggregate and cementitious matrix that results denser and less porous than conventional concretes. However, if a bad quality cementitious matrix or a high water/cement ratio is employed property enhancements are less important.

Table 1. Physical properties of EAF slag compared to dolomitic aggregate (NA).

\begin{tabular}{lcccc}
\hline & $\begin{array}{c}\text { Apparent density } \\
\left(\mathrm{kg} / \mathrm{m}^{3}\right)\end{array}$ & $\begin{array}{c}\text { Water } \\
\text { absorption }(\%)\end{array}$ & $\begin{array}{c}\text { Porosity } \\
(\%)\end{array}$ & Shape \\
\hline EAF slag $0-4 \mathrm{~mm}$ & 3800 & $1.0-1.5$ & 2.0 & Crushed \\
\hline EAF slag $4-16 \mathrm{~mm}$ & 3950 & $<1.0$ & $0.5-2-7$ & Crushed \\
\hline NA 0-4 $\mathrm{mm}$ & 2760 & 1.01 .5 & $<2.0$ & Roundish \\
\hline NA 4-16 mm & 2790 & $<0.5$ & $0.9-1.8$ & Roundish \\
\hline
\end{tabular}

To analyze the structural response of buildings built with different concrete mixtures, threemoment frame RC structures with 3-, 6- and 9- stories were considered. The structures are

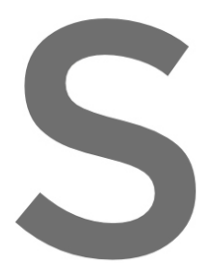
characterized by a regu three in the transversal

The structures were

(Municipality of Pordenction Building Code consider
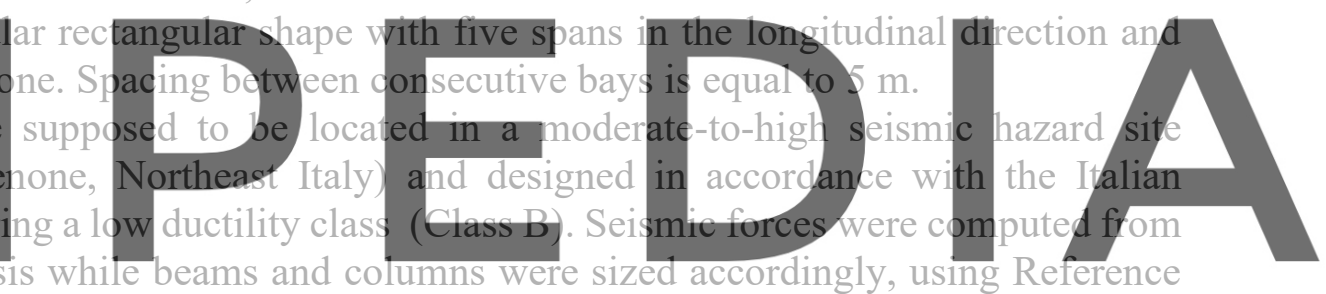

a dynamic linear anal $25 / 30$ strength class.

Register for free at https//www.scipedia.com to download the version without the watermark

a)

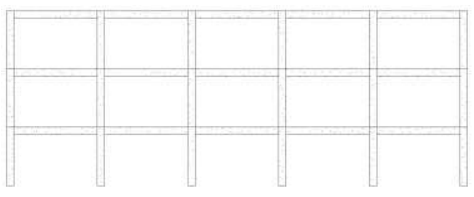

b)

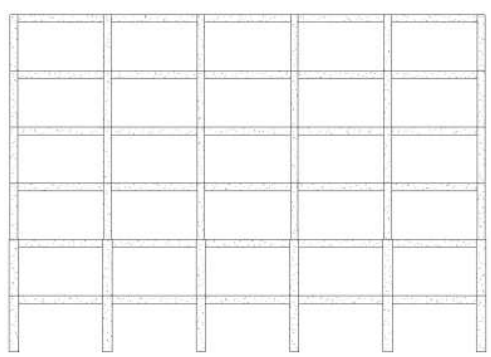

c)

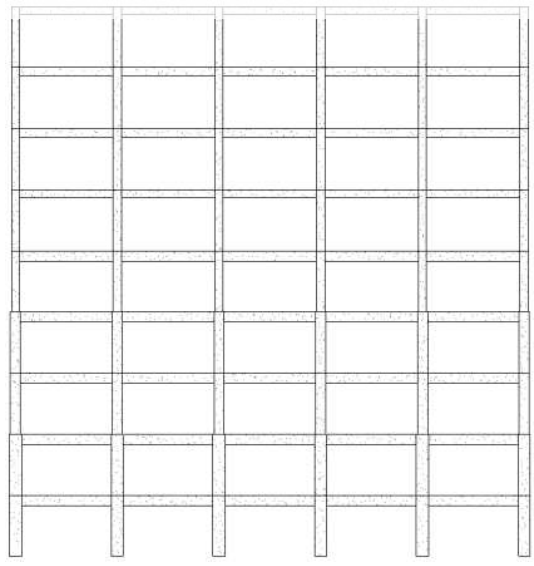

Figure 1. RC frame layouts analyzed: floor plan (a), 3- (b), 6- (c) and 9-story (d) building archetypes. 


\section{Seismic Reliability Analysis}

For the Performance-Based Earthquake Engineering (PBEE) framework (Cornell et al., 2000) the occurrence of mainshock events at a given site is assumed to be a Homogenous Poisson Process. Neglecting damage accumulation on structure, the process of events causing the structural failure is also represented by an HPP, whose unique parameter, the failure rate $\lambda_{f}$, can be used for computing the failure probability in any time interval. Particularly, it depends on the hazard curve $\left(\lambda_{i m}\right)$, representing the seismicity on a specific site, and on fragility curve $(P[f \mid i m])$ being the probabilistic structural behavior of a specific structure. $\lambda_{f}$ can be computed by applying the Total Probability Theorem in the following way:

$$
\lambda_{f}=\int_{i m} P[f \mid i m] \cdot\left|d \lambda_{i m}\right|
$$

Once estimated the failure rate, based on the HPP assumption it is possible to quantify the probability of failure for a given time window of interest $t$ due to earthquake occurrences:

$$
P_{E, f}=1-e^{-\lambda_{f} t}
$$

and further, derive the seismic reliability index $\left(\beta_{E, t}\right)$ in accordance with the reliability analysis theory with the following transformation:

$$
\beta_{E, t}=-\Phi^{-1}\left(P_{E, f}\right)
$$

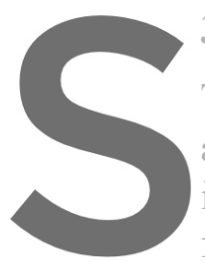

\subsection{Seismic hazard ant \\ To compute $\lambda_{i m}$, seism and Volcanology (ING is needed. Since INGV

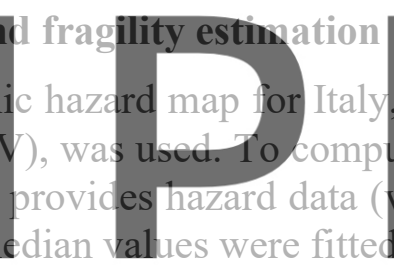

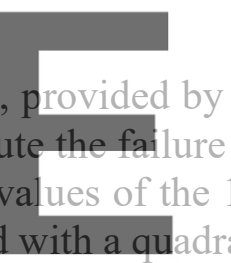
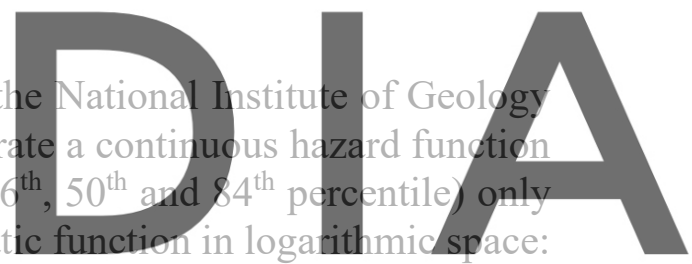

. $\lambda(s)=k_{0} e^{\left(-k_{1} \ln (s)-k_{2} \ln ^{2}(s)\right)}$

Register for free at https//www.scipedia.com to download the version without the watermark

In assessing seismic reliability, instead of the median hazard curve, it is more suitable to

refer to the mean one which is possible to derive with the following equation:

$$
\bar{\lambda}(s)=\lambda(s) e^{\left(\frac{1}{2} \beta_{H}^{2}\right)}
$$

Where $\beta_{H}$ can be estimated as:

$$
\beta_{H}=\frac{\ln \left(S_{84 \%}\right)-\ln \left(S_{16 \%}\right)}{2}
$$

The fragility function $(P[f \mid i m])$ represents the probability to reach and exceed a certain damage state given a specific intensity im. In this work, Cloud Analysis method (Jalayer\&Cornell, 2003) is adopted. The fragility parameters are estimated starting from a set of $\mathrm{n}$ natural ground motion records and the fragility function is computed as follows:

$$
[f \mid i m]=P[E D P>\overline{e d p} \mid i m]=1-P[E D P \leq \overline{e d p} \mid i m]=1-\Phi\left[\frac{\ln (\overline{e d p})-\ln (e d p)}{\beta}\right]
$$

$\overline{e d p}$ is the median threshold value of the assumed structural limit state, and $e d p$ represents the median estimate of the demand that can be computed with a ln-linear regression model, as: 


$$
\ln (e d p)=a+b \cdot \ln (\mathrm{im})
$$

$\beta$ is the standard deviation of the demand conditioned on $i m$ and can be estimated from the regression of the seismic demands as:

$$
\beta_{H}=\frac{\ln \left(S_{84 \%}\right)-\ln \left(S_{16 \%}\right)}{2}
$$

\section{Seismic Reliability Assessment of the EAF RC Frame Archetypes}

For the NLTHAs a diffused plasticity model, using a fiber section discretization, was adopted to consider material non-linearities. Unconfined and confined concrete was modeled via the Mander et al. (1988) model whereas the Menegotto-Pinto (1973) steel model was used for the non-linear behavior of rebars. Simulations were carried out via SeismoStruct software and a set of 30 natural unscaled ground motion records were adopted using all three components of the seismic wave. EAF concrete characteristics are computed using the ratio coefficients in Table 2 and the reference concrete material (C25/30) characteristics.

Table 2. Ratios between EAF and Reference concrete properties.

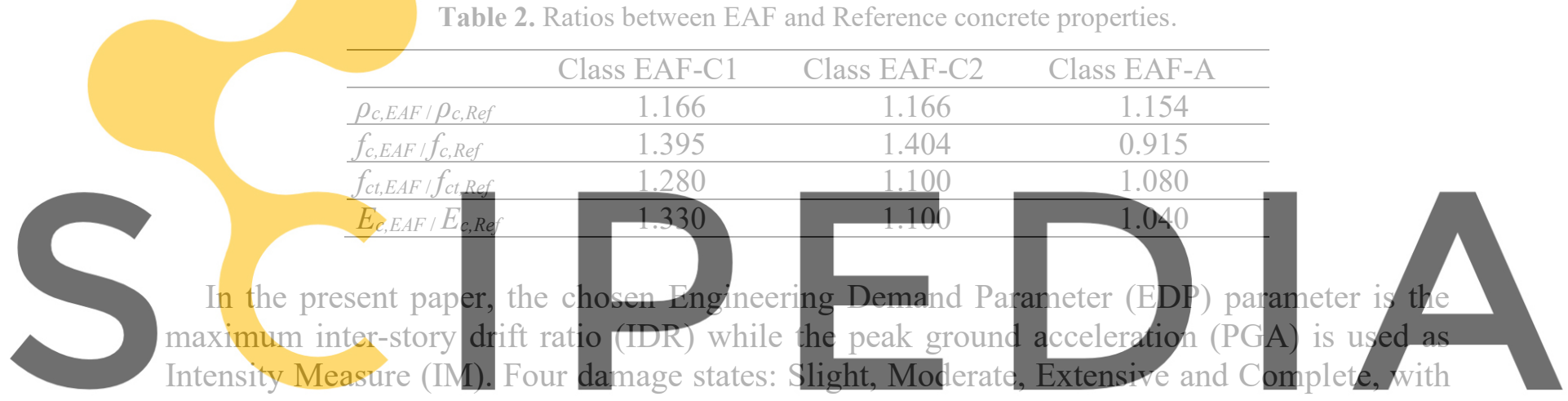
corresponding EPD threshold of $0.4 \%, 0.8 \%, 1.5 \%$ and $3 \%$, were defined. Threshold values

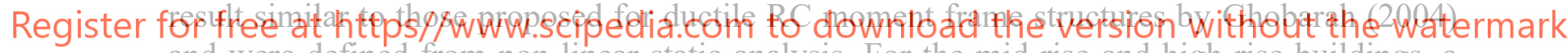
and were defined from non-linear static analysis. For the mid-rise and high-rise buildings, a reduction factor of respectively $2 / 3$ and $1 / 2$ as proposed by FEMA (2012) was considered to account for higher mode effects and differences between average computed in non-linear static analysis and maximum individual IDR from NLTHAs.

\section{Results and Discussion}

Structural response was evaluated with respect to the four damage states previously defined, varying from Slight to Complete. Fragility functions were computed for each of the 12 cases, resulting from different geometrical and material combinations, using the Cloud Method described in Section 3.1 (Figure 2). A comparison of the seismic performance of structures built with the reference concrete and EAF concrete is given in Figure 2 with the fragility curves and the reliability index in Figure 3.

It can be noted that the overall performance of EAF concrete structures is close to the performance of the reference material one. The 6- story model has shown almost the same response for all considered materials, proven by overlapping fragility curves, while the 3- and 9- story curves tend to vary more when considering different materials. 
a)

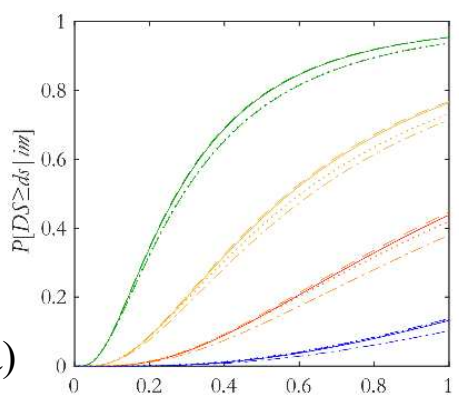

b)

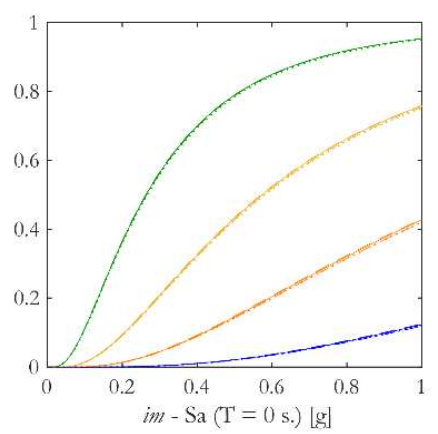

c)

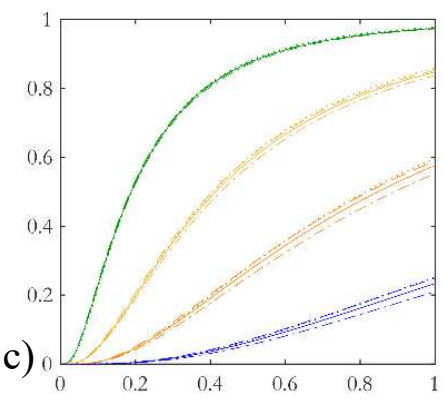

Figure 2. Slight, Moderate, Extensive and Complete DS fragility curves for 3- (a), 6- (b) and 9- (c) story RC frame archetypes (Solid - reference (C25/30); Dotted - EAF-C1; Dashed - EAF-C2; Dash-dot - EAF-A).
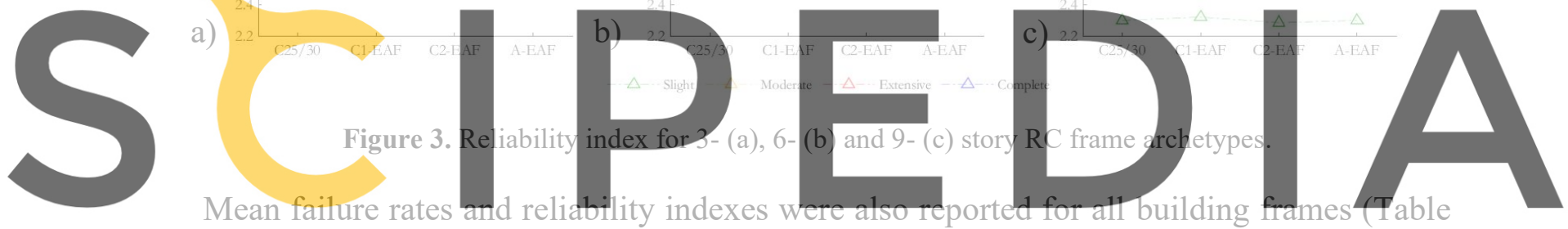

3). When compared to the reference material, EAF concrete buildings report similar reliability

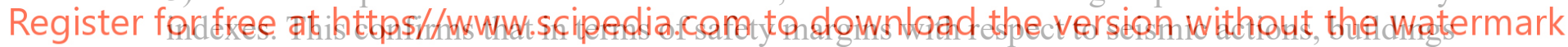

designed with ordinary concrete but built with EAF aggregates are exposed to almost the same

risk as those built with NAs ones.

This highlights that NAs replacement with EAF aggregates, in the same structural system, has a small impact in terms of seismic reliability levels achieved. The difference in the mean failure rate of the 9-story building and those of the 3- and 6-story ones may be due to the reduced damage states EDP threshold adopted for the 9- story by considering it a high-rise building. It also points out that current code recommendations do not guarantee building design characterized by the same level of seismic reliability but often some differences can be observed, especially when comparing different rise buildings.

Table 3. Comparison between mean failure rates and reliability indexes ( $\beta$ ) derived for 3-, 6- and 9-story RC frame archetypes.

\begin{tabular}{cccccccccc}
\hline DS & Story & \multicolumn{2}{c}{ C25/30 } & \multicolumn{2}{c}{ C1-EAF } & \multicolumn{2}{c}{ C2-EAF } & \multicolumn{2}{c}{ A-EAF } \\
\hline \multirow{3}{*}{ Slight } & & $\lambda_{f}$ & $\beta$ & $\lambda_{f}$ & $\beta$ & $\lambda_{f}$ & $\beta$ & $\lambda_{f}$ & $\beta$ \\
& $3-$ & $4.31 \mathrm{E}-03$ & 2.63 & $4.28 \mathrm{E}-03$ & 2.63 & $4.37 \mathrm{E}-03$ & 2.62 & $4.22 \mathrm{E}-03$ & 2.63 \\
& $6-$ & $4.97 \mathrm{E}-03$ & 2.58 & $4.91 \mathrm{E}-03$ & 2.58 & $5.05 \mathrm{E}-03$ & 2.57 & $4.94 \mathrm{E}-03$ & 2.58 \\
& $9-$ & $1.08 \mathrm{E}-02$ & 2.30 & $1.02 \mathrm{E}-02$ & 2.32 & $1.12 \mathrm{E}-02$ & 2.29 & $1.08 \mathrm{E}-02$ & 2.30 \\
\hline
\end{tabular}




\begin{tabular}{llllllllll}
\hline \multirow{3}{*}{ Moderate } & $3-$ & $8.98 \mathrm{E}-04$ & 3.12 & $9.23 \mathrm{E}-04$ & 3.11 & $9.23 \mathrm{E}-04$ & 3.11 & $8.27 \mathrm{E}-04$ & 3.15 \\
& $6-$ & $9.93 \mathrm{E}-04$ & 3.09 & $9.77 \mathrm{E}-04$ & 3.10 & $1.01 \mathrm{E}-03$ & 3.09 & $9.76 \mathrm{E}-04$ & 3.10 \\
& $9-$ & $2.46 \mathrm{E}-03$ & 2.81 & $2.39 \mathrm{E}-03$ & 2.82 & $2.61 \mathrm{E}-03$ & 2.79 & $2.34 \mathrm{E}-03$ & 2.83 \\
\hline \multirow{3}{*}{ Extensive } & $3-$ & $1.80 \mathrm{E}-04$ & 3.57 & $1.93 \mathrm{E}-04$ & 3.55 & $1.88 \mathrm{E}-04$ & 3.56 & $1.55 \mathrm{E}-04$ & 3.61 \\
& $6-$ & $1.89 \mathrm{E}-04$ & 3.56 & $1.85 \mathrm{E}-04$ & 3.56 & $1.94 \mathrm{E}-04$ & 3.55 & $1.83 \mathrm{E}-04$ & 3.56 \\
& $9-$ & $5.27 \mathrm{E}-04$ & 3.28 & $5.30 \mathrm{E}-04$ & 3.27 & $5.78 \mathrm{E}-04$ & 3.25 & $4.80 \mathrm{E}-04$ & 3.30 \\
\hline \multirow{3}{*}{ Complete } & $3-$ & $2.43 \mathrm{E}-05$ & 4.06 & $2.76 \mathrm{E}-05$ & 4.03 & $2.58 \mathrm{E}-05$ & 4.05 & $1.90 \mathrm{E}-05$ & 4.12 \\
& $6-$ & $2.36 \mathrm{E}-05$ & 4.07 & $2.31 \mathrm{E}-05$ & 4.07 & $2.45 \mathrm{E}-05$ & 4.06 & $2.26 \mathrm{E}-05$ & 4.08 \\
& $9-$ & $7.71 \mathrm{E}-05$ & 3.78 & $8.13 \mathrm{E}-05$ & 3.77 & $8.80 \mathrm{E}-05$ & 3.75 & $6.58 \mathrm{E}-05$ & 3.82 \\
\hline
\end{tabular}

\section{Conclusions}

The main goal of this paper was to investigate the effect of concrete mixtures with EAF slag in the seismic performance of different code conforming RC-frame structures (3-, 6- and 9stories). The impact of EAG slag in mass and stiffness variation can lead to different seismic loads and global response of the building. A seismic reliability assessment was carried out and fragility functions, mean failure rates, and reliability indexes were computed for each combination of geometrical configuration and material. Based on the results of the present study the following conclusions can be highlighted:

Using materials that were proved to have higher mechanical strength than the reference one, might not improve the global seismic behavior of the structure.
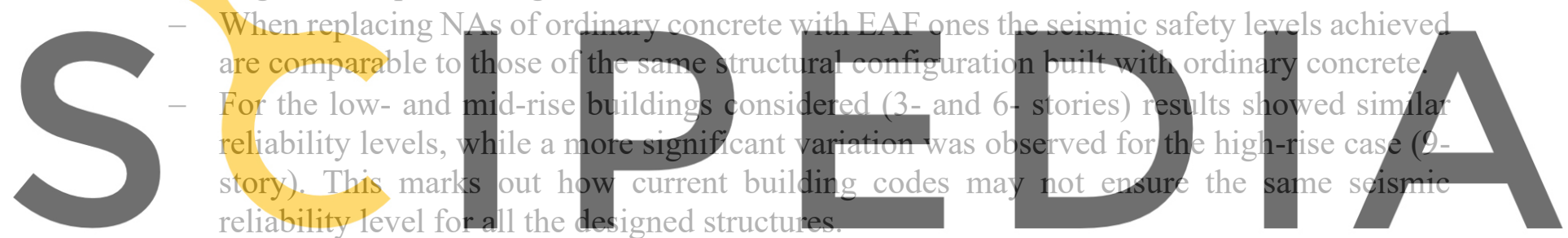

Register fORFree at https//www.scipedia.com to download the version without the watermark Flora Faleschini: https://orcid.org/0000-0003-2126-9300

Mariano A. Zanini: https://orcid.org/0000-0001-9326-802X

Klajdi Toska: https://orcid.org/0000-0002-4131-7683

\section{References}

Arribas I., Santamaría A., Ruiz E., Ortega-López V. and Manso J.M. (2015). Electric arc furnace slag and its use in hydraulic concrete. Constr Build Mater 90: 68-79. doi: 10.1016/j.conbuildmat.2015.05.003.

Cornell C.A. and Krawinkler H. (2000). Progress and challenges in seismic performance assessment. PEER Centre News, 3(2): 1-3.

De Domenico D., Faleschini F., Pellegrino C. and Ricciardi G. (2018). Structural behavior of RC beams containing EAF slag as recycled aggregate: Numerical versus experimental results. Constr Build Mater 171: 321-337. doi: 10.1016/j.conbuildmat.2018.03.128.

DM 17/01/2018 (2018). Aggiornamento delle Norme Tecniche per le Costruzioni, Roma, Italy. (in Italian)

EN 12620 (2008). Aggregates for concrete. Comité Européen de Normalisation, Brussels, Belgium.

Faleschini F., Alejandro Fernández-Ruíz M., Zanini M.A., Brunelli K., Pellegrino C. and Hernández-Montes E. (2015). High performance concrete with electric arc furnace slag as aggregate: mechanical and durability properties. Constr Build Mater 101, 113-121. doi: 10.1016/j.conbuildmat.2015.10.022

Faleschini F., Santamaria A., Zanini M.A., San José J.-T. and Pellegrino C. (2017). Bond between steel reinforcement bars and Electric Arc Furnace slag concrete. Mater Struct 50: 170. doi: 10.1617/s11527-017- 
1038-2.

Faleschini F., Hofer L., Zanini M.A., Dalla Benetta M. and Pellegrino C. (2017). Experimental behavior of beamcolumn joints made with EAF concrete under cyclic loading. Eng Struct 139: 81-95. doi: 10.1016/j.engstruct.2017.02.038.

Faleschini F., Bragolusi P., Zanini M.A., Zampieri P. and Pellegrino C. (2017). Experimental and numerical investigation on the cyclic behavior of RC beam column joints with EAF slag concrete. Eng Struct 152: 335 347. doi: 10.1016/j.engstruct.2017.09.022.

FEMA (2012). Earthquake Model, Hazus-MH 2.1 Technical Manual. Federal Emergency Management Agency, Washington DC, US (available at: www.fema.gov/plan/prevent/hazus).

FHWA (1997). User Guidelines for Waste and Byproduct Materials in Pavement Construction. Federal Highway Administration Research and Technology Report no. FHWA-RD-97-148.

Ghobarah A. (2004). On drift limits associated with different damage levels. International workshop on Performance based design: concepts and implementations, 28 June- 1 July 2004.

INGV. Interactive Seismic Hazard Maps. Available at: http://esse1-gis.mi.ingv.it/s1_en.php (last access 04/03/2019).

Jalayer F. and Cornell C.A. (2003). Direct probabilistic seismic analysis: implementing non-linear dynamic assessments. Stanford University

Liapis A., Anastasiou E.K., Papachristoforou M. and Papayianni I. (2018). Feasibility Study and Criteria for EAF Slag Utilization in Concrete Products. J Sustain Metall 4(1): 68-76. doi: 10.1007/s40831-017-0152-2.

Lee J.-M,, Lee Y.-J., Jung Y.-J., Park J.-H., Lee B.-S. and Kim K.-H. (2018). Ductile capacity of reinforced concrete columns with electric arc furnace oxidizing slag aggregate. Constr Build Mater 162: 781-793. doi: 10.1016/j.conbuildmat.2017.12.045

Mander J.B., Priestley M.J.N., and Park R. (1988). Theoretical stress-strain model for confined concrete. Journal of Structural Engineering, 114(8): 1804-1826.

Menegotto M. and Pinto P. E. (1973). Method of analysis for cyclically loaded reinforced concrete plane force and bending. In Proceedin on by Well Defined Repe

Ortega-López V., Fuente-A fiber-reinforced EAF 10.1016/j.conbuildmat.2017.12

Pellegrino C. and Gaddo
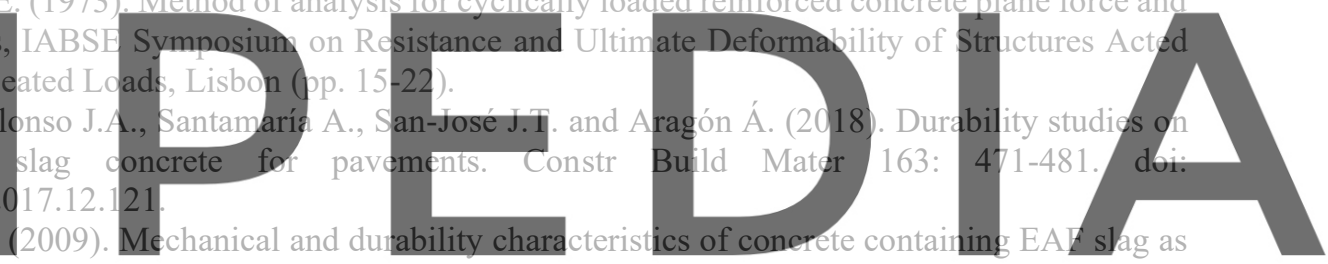
aggregate. Cem Concr Compos 31(9): 663-671. doi: 10.1016/j.cemconcomp.2009.05.006.

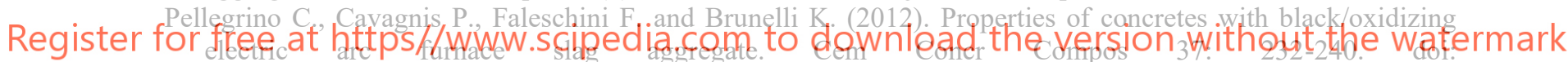
10.1016/j.cemconcomp.2012.09.001

Pellegrino C. and Faleschini F. (2013). Experimental behavior of reinforced concrete beams with electric arc furnace slag as recycled aggregate. ACI Mater. J. 110: 197-206.

Pellegrino C. and Faleschini F. (2016). Experimental Database of EAF Slag Use in Concrete. in: Sustainability Improvements in the Concrete Industry. Springer, Switzerland. doi: 10.1007/978-3-319-28540-5.

Pomaro B., Gramegna F., Cherubini R., De Nadal V., Salomoni V. and Faleschini F. (2019). Gamma-ray shielding properties of heavyweight concrete with Electric Arc Furnace slag as aggregate: An experimental and numerical study. Constr Build Mater 200: 188-197.

Qasrawi H. (2014). The use of steel slag aggregate to enhance the mechanical properties of recycled aggregate concrete and retain the environment. Constr Build Mater 54: 298-304. doi: 10.1016/j.conbuildmat.2013.12.063.

Rondi L., Bregoli G., Sorlini S., Cominoli L., Collivignarelli C. and Plizzari G. (2016). Concrete with EAF steel slag as aggregate: A comprehensive technical and environmental characterisation. Compos Part B 90: 195-202. doi: 10.1016/j.compositesb.2015.12.022.

SeismoSoft (2013). SeismoStruct - a computer program for static and dynamic nonlinear analysis of frames structures. Available at: http://www.seismosoft.com.

United Nations (2015). Resolution adopted by the General Assembly on 25 September 2015. 70/1. Transforming our world: the 2030 Agenda for Sustainable Development.

Zanini M.A. (2019). Structural reliability of bridges realized with reinforced concretes with electric arc furnace slag aggregates. Eng Struct 188, 305-319. 